\title{
Breast reduction and subsequent cancer: A prophylactic perspective
}

\author{
Beniamino Palmieri ${ }^{a, *}$, Giorgia Benuzzi $^{\mathrm{a}}$, Alberto Costa $^{\mathrm{b}}$, \\ Simone Grappolini ${ }^{\mathrm{C}}$
}

\author{
${ }^{a}$ Department of General Surgery and Surgical Specialties, University of Modena and Reggio Emilia, \\ Clinica Chirurgica, Via del Pozzo, 71, 41100 Modena, Italy \\ ${ }^{\mathrm{b}}$ Department of Surgery, Fondazione Maugeri, Pavia, Italy \\ ${ }^{\mathrm{c}}$ Department of Plastic Surgery, Fondazione Clinica Humanitas, Milano
}

Received 10 January 2005; received in revised form 21 September 2005; accepted 29 September 2005

\section{KEYWORDS}

Breast cancer;

Breast hypertrophy;

Breast reduction;

Gigantomastia

\begin{abstract}
Summary The aim of this paper was to evaluate the impact of breast-gland remodelling, for cosmetic or functional purposes, on cancer incidence during longterm post-surgical follow-up. We reviewed the literature investigating the ratio between the amount of breast tissue resected and cancer incidence during followup. Our analysis of the published data suggested that hypertrophic breast remodelling decreases the risk of breast and other types of cancer in post-operative patients. The actual risk reduction for patients over 40 years of age is related to the weight of the surgical specimens during the previous operation. Our conclusions support the use of breast-reduction surgery as a preventive measure in patients complaining of symptomatic breast enlargement, especially those with a family history of breast cancer.

(c) 2005 Elsevier Ltd. All rights reserved.
\end{abstract}

\section{Introduction}

Breast reduction (BR), or reduction mastoplasty, is a plastic procedure based on different surgical techniques, which aims to reduce the breast volume when it is affecting the patient's quality of life.

\footnotetext{
*Corresponding author. Tel.: +39594222483; fax: +39594224370 .

E-mail address: palmieri@unimo.it (B. Palmieri).
}

In this work, we review the available clinical studies (Tables 1 and 2), and attempt to outline future developments of the BR technique that could increase its cancer-preventive impact and effectiveness.

\section{BR and cancer during long-term follow-up}

The earliest report, by Lund et al., ${ }^{1}$ described 1245 women aged between 20 and 70 years who had 


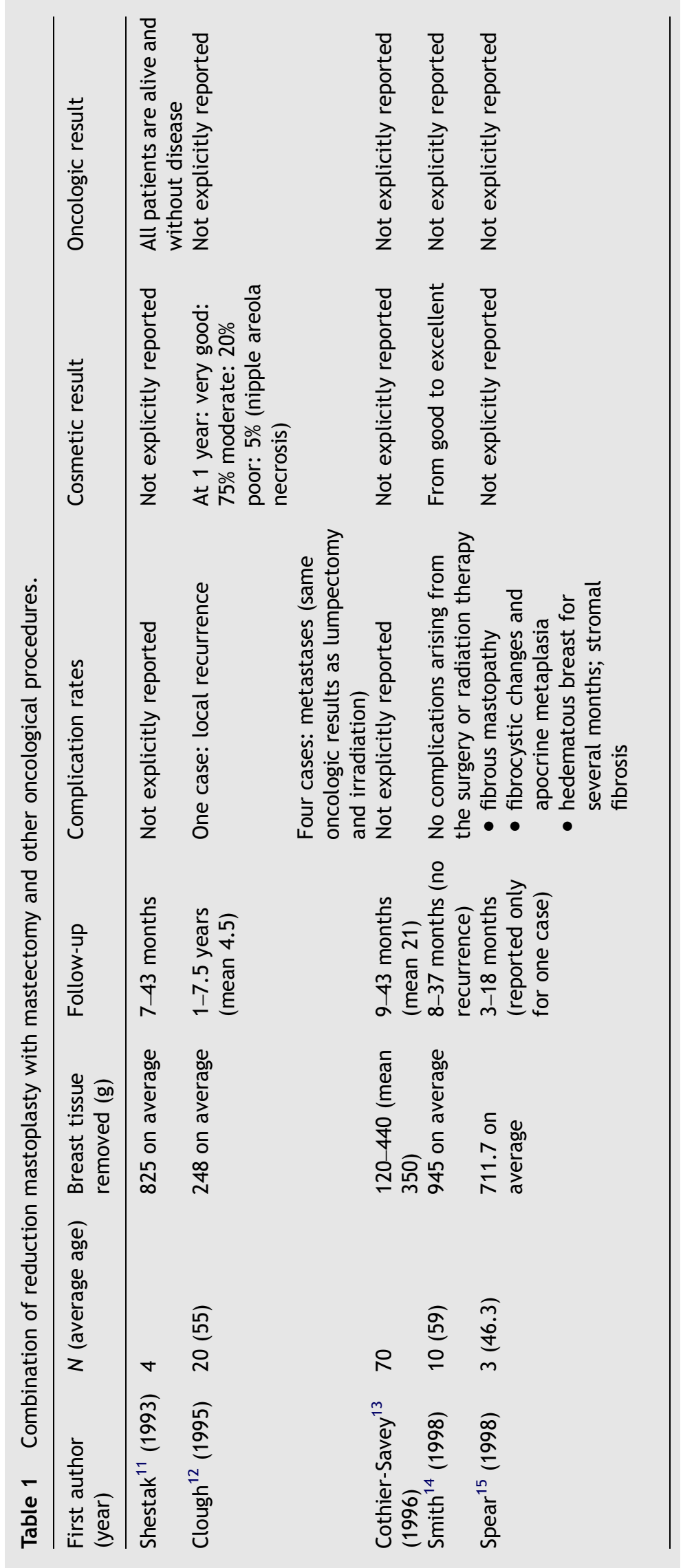


Table 2 Breast cancer found at the time of reduction mammaplasty.

\begin{tabular}{|c|c|c|c|c|}
\hline $\begin{array}{l}\text { First author } \\
\text { (year) }\end{array}$ & $N$ (average age) & $\begin{array}{l}C_{F} \text { (number of } \\
\text { breast cancers } \\
\text { found among } N \text { ) }\end{array}$ & $C_{F}$ and cancer location & Follow-up \\
\hline Petit $^{16}$ (1997) & 440 & 22 & $\begin{array}{l}\text { In RM, } 20 \text { occult } 4.6 \% \text { In lower and } \\
\text { central quadrants }(70 \%)\end{array}$ & $\begin{array}{l}\text { Not explicitly } \\
\text { reported }\end{array}$ \\
\hline Jansen $^{5}$ (1998) & 2576 & 4 & $\begin{array}{l}\text { Two cases not found preoperatively } \\
\text { by mammography and self- } \\
\text { examination }\end{array}$ & $\begin{array}{l}2 \text { years free of } \\
\text { cancer }\end{array}$ \\
\hline Tang $^{8}$ (1999) & 27,500 & 17 & $\begin{array}{l}\text { Breast cancer found at } 49 \text { years old } \\
\text { for women undergoing RM (average } \\
\text { age at diagnosis: } 61 \text { years old) }\end{array}$ & 8 years \\
\hline Brown $^{6}$ (1999) & 27,500 & 18 & Breast cancer & $\begin{array}{l}\text { Average } 6.5 \\
\text { years }\end{array}$ \\
\hline $\begin{array}{l}\text { Keleher }^{17} \\
(2003)\end{array}$ & 4 & 4 & $\begin{array}{l}4 \text { cases not found preoperatively by } \\
\text { mammography and self- } \\
\text { examination at M.D. Anderson } \\
\text { Cancer }\end{array}$ & $1-6$ months \\
\hline
\end{tabular}

undergone BR in Denmark between 1943 and 1971 using different surgical procedures. The authors observed 18 cases of breast cancer versus 30.28 expected cases, with a relative risk (RR) - defined as the ratio between the observed and expected cancers-of 0.39 .

In the first 10 years of follow-up, five cases were detected versus 7.11 expected cases, while after 10 years of follow-up, 13 cases were detected versus 23.17 expected cases. The greatest cancerrisk reduction was experienced by women who had at least $600 \mathrm{~g}$ of tissue surgically removed $(\mathrm{RR}=0.31 ; \quad 95 \%$ confidence interval $[\mathrm{CI})]$ 0.06-0.91).

Nine years later, Baasch et al. ${ }^{2}$ followed-up the original study group of Lund et al. The authors calculated the RR as 0.61 and supported the previous observation that $600 \mathrm{~g}$ was the minimum critical mass of resected tissue to achieve a significant cancer-risk reduction.

In the above-mentioned long-term follow-up (19 years) of 1240 patients, 32 cancers were observed versus 52.55 expected cancers. Women who underwent surgery at the age of 20 had a more or less increased, but not statistically significant, risk of malignancy compared with the general population or other age groups. In the Copenhagen series, a $30 \%$ reduction in risk was seen among women aged between 21 and 40 years during long-term followup. A total of $20.7 \%$ of the patients aged 40 years or above were nulliparous compared with $20 \%$ of the general population; in addition, the mean number of children was 1.7 and the mean age at the first birth was 24.0 years, both of which were similar to the figures for the general population. The longterm follow-up did not show any specific trend towards cancerisation. The population compliance with X-ray screening to detect preoperative small cancers in women aged over 50 years could explain the substantial reduction in tumour incidence during the 5-year follow-up (two versus 12 expected, while no such effect was seen in those aged under 50 years (12 cancers observed versus 12.2 expected. Significant variation was seen depending on the type of technique, date of operation, place of surgery and quadrant.

Regarding the relationship between cancer incidence and age, it should be noted that the younger women tended to be slimmer and have larger breasts than the older women; that is, the older women were often overweight or obese. This may have increased the risk of tumourigenesis and also the protection offered by BR surgery. In fact, surgery not only reduced the glandular mass that could potentially become malignant, but also removed a large number of adipocytes in the fat tissue, which are responsible for enhancing the hormonal co-carcinogenic potential by transforming androstenedione into estrogens via aromatase.

Brinton et al. ${ }^{3}$ carried out a small populationbased case-control study on BR and cancer, which formed part of an investigation into surgical breast enlargement that included 2174 patients and 2009 controls with previous breast implants, 10 reductive mammoplasties and 13 controls. In the prosthesis group, the observed percentage of cancers-36 cases $(11 \%)$ versus 44 (2\%) - of the controls showed a reduction in the RR of 0.2 and an 
RR value of 0.8 for both localised and distant tumours; the reduction of risk in reductive mastoplasties was $0.7 \%$ ( $95 \% \mathrm{Cl} 0.4-1.0)$.

Boice et al. $^{4}$ examined the Danish hospital discharge registry records of 7720 women who underwent BR between 1977 and 1992, with a specific focus on the risk according to age and time since surgery. The median age at time of surgery was 46 years and the mean length of follow-up was 7.5 years. A total of 182 cancers of various types were observed during the follow-up versus 209 expected tumours (standardised incidence ratio $[S I R]=0.9 \% ; 95 \% \mathrm{Cl} 0.7-1.0)$. Specifically, breast cancer was reduced by roughly $50 \%$ ( 29 observed tumours versus 53.9 expected tumours; $R R=0.54$ ). Patient age at surgery was a significant factor; the risk was reduced at the age of 40 years and an overall reduction of $70 \%$ was observed at 50 years of age.

The types of cancer observed among these patients were ductal carcinomas (65\%), alveolar cancers (19\%) and ductal carcinoma in situ (DCIS; $16 \%)$.

Jansen et al. ${ }^{5}$, in a retrospective study of 2576 BRs, reported four cases $(0.16 \%)$ of intra-operative cancer detection that escaped routine mammography, self-examination and physical examination by the surgeons. This different rate of incidental tumour discovery at the time of reduction surgery might be explained on the basis of differences in the accuracy of preoperative breast examinations. Nearly 660 patients with pre-existing breast cancer were subsequently found not to be at risk in terms of the contralateral operated breast, which was exposed to a high risk of cancer.

Brown et al. ${ }^{6}$ used the Canadian Institute for Health databank to identify 30137 women who submitted to bilateral $(94.7 \%)$ or unilateral $(5.3 \%)$ BR between 1979 and 1992. The final eligible cases comprised 26,567 bilateral reductions and 933 unilateral reductions. Of the latter group, 412 patients had prior breast cancer, 314 patients had prior or synchronous cancer, 87 patients $(27.7 \%)$ had specific breast cancer and 18 cases were detected during the operation. Among the 26,567 women who underwent surgery, 101 cancers were observed versus 165.8 expected cancers, yielding an RR of 0.61 (95\% Cl 0.50-0.74). Regarding other primary cancers, 285 cases were observed versus 372.5 expected cases, with an RR of $0.77(95 \% \mathrm{Cl}$ $0.68-0.86)$.

Lung cancer, cervical carcinoma and non-colorectal gastrointestinal tract tumours were most frequently observed and had clearly reduced risks $(0.59,0.51$ and 0.58 , respectively). These beneficial effects were probably due to post-operative lifestyle changes, such as stopping smoking, increasing physical activity and reducing body weight.

Evaluating the breast cancer incidence during the first 10 years post-operation, 86 cases were observed versus 147 expected cases. The remaining 15 cases occurred 10-14 years after the initial surgery. Thus, the relative risk in the first 10 years was $0.59(95 \% \mathrm{Cl} 0.47-0.72)$, which rose to $0.80(95 \% \mathrm{Cl} 0.45-1.32)$ during the following 4 years. No difference in risk was observed between groups evaluated by age according to decade.

Tang et al. ${ }^{7,8}$ reported on a cohort study of breast cancer risk in BR patients $(27,500$ cases; 101 cancers detected) following a contemporary report by Brown that showed a $40 \%$ reduction in the risk of developing breast cancer after BR. In the retrospective survey, the author described the diagnosis of cancer between 3 months and 13 years after mammaplasty, with a median of 5 years. The median age of the patients when they submitted to reduction surgery was 50 years and the average age at cancer detection was 55 years; this was significantly younger than the average age of cancer detection in the general population $(61$ years). This difference could be explained in terms of the increased attention and awareness among women who have undergone BR surgery, coupled with the greater ease of physical and instrumental exploration allowed by the reduced volume of parenchyma. The histology and distribution were similar to those of the control cases, as were the surgical and oncological protocols employed. The survival rate at 5 years was $70 \%$ in the breastreduction group and $77 \%$ in the control group; this difference was not statistically significant, as confirmed by the overlapping of the lower and upper confidence levels.

Boice et al. ${ }^{9}$ investigated the oncologic impact of BR on 31,910 women, excluding those with cancers occurring before or within 3 months of surgery. The mean age at surgery was 33 years and the mean length of follow-up was 7.5 years. A total of 662 cancers were observed versus 729 expected cancers $(\mathrm{SIR}=0.91 ; 95 \% \mathrm{Cl} 0.84-0.98)$ with a $28 \%$ breast cancer reduction (161 detected versus 223 expected; SIR 0.72; 95\% Cl 0.61-0.84). Lung cancer was also reduced $(S I R=0.73)$ as was melanoma $(\mathrm{SIR}=0.72)$. By contrast, corpus uteri cancer $(S I R=1.37)$, thyroid cancer $(S I R=1.39)$, other endocrine tumours $(S I R=1.55)$ and parathyroid adenomas $(S I R=1.51)$ were all increased postoperatively. In addition, the inverse association between age at surgery and cancer risk was confirmed in this study; in fact, the risk was 
reduced by $24 \%$ and $43 \%$ in the groups aged $40-49$ and over 50 years, respectively.

Brinton et al. ${ }^{10}$ focused their investigation on the influence of the amount of tissue removed during reduction mammoplasty on breast cancer risk. They examined 137 BR specimens and 422 control patients. Subjects who had more than $800 \mathrm{~g}$ of tissue removed had a $76 \%$ lower risk relative to those who had more than $400 \mathrm{~g}$ of tissue removed from either breast, irrespective of age at surgery. The weak protection from cancer observed in patients who underwent surgery before the age of 40 years was probably related to the lower volume of tissue removed, due to the relatively lower weights of younger women compared with older women; the genetic impact of cancer early in life could also have had an effect. A longer follow-up would therefore allow more accurate evaluation of the effects on lifespan.

\section{Discussion}

Our review identified a consensus in the literature, that is, the removal of a critical amount of gland and fat tissue significantly lowered the breast cancer incidence in the operated cohort of patients during long-term follow-up ${ }^{11-17}$ (Tables 1 and 2).

In addition, symmetric contralateral BR after modified mastectomy and breast reconstruction of the opposite site had an oncologically preventive rationale. In fact, the increased cancer risk due to exposure to potentially carcinogenic factors was counteracted by gland-tissue subtraction.

When breast enlargement has reached a symptomatic clinical threshold, gland reduction should be recommended not only as a restorative procedure for the patient's fitness and wellbeing, but also for the effective removal of ageing gland tissue, thereby preventing cancer onset.

Many women might submit to bilateral BR if the oncologic prevention of a second primary cancer could be achieved. Among the women who underwent reduction mastoplasty, a cancer risk reduction was also observed in terms of tumours affecting other organs, such as the lung or Gl tract. The mechanism of the reduction in cancer risk due to the removal of breast gland and fat tissue remains unclear. However, changes in lifestyle, which are probably related to improved self-esteem and image, as well as the relief or disappearance of arthro-muscular pain and discomfort, might give a partial explanation of this phenomenon.

Under our developmental strategies, BR techniques should aim for radical gland subtraction, leaving no tissue in the nipple-areola complex
(NAC), according to our previously described twostep nipple-sparing subcutaneous mastectomy technique, ${ }^{18}$ and remodelling the plentiful subcutaneous fat against the potential background of a submuscular prosthesis. The problem of NAC transposition (that is, uplifting the complex together with the newly formed dermal vascular pedicle in order to achieve satisfying cosmetic results) is a major issue, especially in large hypertrophies where substantial NAC mobilisation is required.

Another problem that requires careful intraoperative evaluation is the final operative field overview in terms of removing all breast gland remnants identified between the remaining fatty tissues. This goal can be obtained by means of transillumination and laparoscopic magnification. In fact, consistent with the Beer et al. report, ${ }^{19}$ the superficial fascia is not present in all breasts and some ducto-alveolar clusters might not be visible macroscopically, thus becoming the substrate for carcinogenic agents during the follow-up, even if the vascular network has been greatly reduced.

The challenge of transforming BR techniques into cosmetic envelope mastectomy techniques with immediate reconstruction is difficult but appealing. It requires not only an adequate technical background and patient compliance from the cosmetic point of view, but also the long-term follow-up of case-control investigations.

However, owing to increased awareness, more surgeons are expected to support the strategy of appealing to middle-aged women in order to improve their life quality, reduce breast cancer incidence and enable more-effective instrumental follow-up. Thus, a larger cohort of operated patients with megalomastia or breast hypertrophy, and some evidence of familial breast cancer or genomic indicators, should be available in future.

\section{References}

1. Lund K, Ewertz M, Schou G. Breast cancer incidence subsequent to surgical reduction of the female breast. Scand J Plast Reconstr Surg Hand Surg 1987;21:209-12.

2. Baasch M, Nielsen SF, Engholm G, Lund K. Breast cancer incidence subsequent to surgical reduction of the female breast. Br J Cancer 1996;73:961-3.

3. Brinton LA, Malone KE, Coates RJ, et al. Breast enlargement and reduction: results from a breast cancer case-control study. Plast Reconstr Surg 1996;97:269-75.

4. Boice Jr JD, Friis S, McLaughlin JK, et al. Cancer following breast reduction surgery in Denmark. Cancer Causes Control 1997;8:253-8.

5. Jansen DA, Murphy M, Kind GM, Sands K. Breast cancer in reduction mammoplasty: case reports and a survey of plastic surgeons. Plast Reconstr Surg 1998;101:361-4. 
6. Brown MH, Weinberg M, Chong N, Levine R, Holowaty E. A cohort study of breast cancer risk in breast reduction patients. Plast Reconstr Surg 1999;103:1674-81.

7. Tang CL, Brown MH, Levine R, Sloan M, Chong N, Holowaty E. A follow-up study of 105 women with breast cancer following reduction mammaplasty. Plast Reconstr Surg 1999; 103:1687-90.

8. Tang CL, Brown MH, Levine R, Sloan M, Chong N, Holowaty E. Breast cancer found at the time of breast reduction. Plast Reconstr Surg 1999;103:1666-82.

9. Boice Jr JD, Persson I, Brinton LA, et al. Breast cancer following breast reduction surgery in Sweden. Plast Reconstr Surg 2000;106:755-62.

10. Brinton LA, Persson I, Boice Jr JD, McLaughlin JK, Fraumeni $\mathrm{Jr}$ JF. Breast cancer risk in relation to amount of tissue removed during breast reduction operations in Sweden. Cancer 2001;91:478-83.

11. Shestak K-C, Johnson R-R, Greco R-J, et al. Partial mastectomy and breast reduction as a valuable treatment option for patients with macromastia and carcinoma of the breast. Surg Gynecol Obstet 1993;177:54-6.

12. Clough K-B, Nos C, Salmon R-J, et al. Conservative treatment of breast cancers by mammaplasty and irradiation: a new approach to lower quadrant tumors. Plast Reconstr Surg 1995;96:363-70.
13. Cothier-Savey I, Otmezguine $\mathrm{Y}$, Calitchi E, et al. [Value of reduction mammoplasty in the conservative treatment of breast neoplasms. Apropos of 70 cases]. Ann Chir Plast Esthet 1996;41:346-53.

14. Smith M-L, Evans G-R, Gurlek A, et al. Reduction mammaplasty: its role in breast conservation surgery for early stage breast cancer. Ann Plast Surg 1998;41:234-9.

15. Spear SL, Burke JB, Forman D, Zuurbier RA, Berg CD. Experience with reduction mammaplasty following breast conservation surgery and radiation therapy. Plast Reconstr Surg 1998; 102:1913-6.

16. Petit JY, Rietjens M, Contesso G, Bertin F, Gilles R. Contralateral mastoplasty for breast reconstruction: a good opportunity for glandular exploration and occult carcinomas diagnosis. Ann Surg Oncol 1997;4:511-5.

17. Keleher AJ, Langstein HN, Ames FC, et al. Breast cancer in reduction mammaplasty specimens: case reports and guidelines. Breast J 2003;9:120-5.

18. Palmieri B, Baitchev G, Grappolini S, Costa A, Benuzzi G. Delayed nipplesparing modified subcutaneous mastectomy: rationale and technique. Breast J 2005; 11:173-8.

19. Beer GM, Varga Z, Budi S, Seifert B, Meyer VE. Incidence of the superficial fascia and its relevance in skin-sparing mastectomy. Cancer 2002;94:1619-25.

Available online at www.sciencedirect.com

$$
\text { science@directo }
$$

